\title{
Analisis Penalaan Kontrol PI D pada Simulasi Kendali Kecepatan Putaran Motor DC Berbeban menggunakan Metode Heuristik
}

\author{
WALUYO, ADITYA FITRI ANSYAH, SYAHRI AL
}

\author{
Jurusan Teknik Elektro Institut Teknologi Nasional (ITENAS) Bandung \\ Email :adityajailani@yahoo.co.id
}

\begin{abstract}
ABSTRAK
Motor DC banyak digunakan di industri kecil dan besar.Kecepatan motor DC sering tidak stabil akibat gangguan dari luar maupun perubahan parameter dan torsi beban sehingga perlu dilakukan rancangan kontroler.Kontroler yang dirancang menggunakan PID yang terdiri dari tiga jenis cara pengaturan yang dikombinasikan, yaitu kontrol P (Proportional), kontrol I (Integral) dan kontrol D (Derivatif).Kontroler yang dirancang disimulasikan menggunakan perangkat lunak. Hasil simulasi menunjukan kontroler PID untuk kendali kecepatan motor DC ini menghasilkan kondisi robust (kokoh) saat nilai $K_{p}=1,1, T_{i}=0,1, T_{d}=3,7$. Hasil dari parameter kendali yang dirancang memiliki error steady state 0,99\% dan dengan settling time 3,7 detik pada rise time 2,00 detik dan nilai peak terletak pada 0,99. Kecepatan awal yang dihasilkan mendekati set point yang diinginkan pada detik ke 6 dan kecepatannya tidak ada penurunan atau tetap konstan sampai dengan detik ke 100.
\end{abstract}

Kata kunci : Motor DC, PID, Heuristik, Steady State, Rise Time

\begin{abstract}
DC motors are widely used in small and large industries. Their speeds are often unstable due to interference from outside or change the parameters and load torque, so that it was necessary to design a controller. The controller was designed using a PIDconsists of three types of arrangements, which are mutually combined way, namely the control $P$ (Proportional), control I (Integral) and control D (Derivative). The controllers were designed using software for simulation. The simulation results showed the PID controller for DC motor speed control produced robust conditionswhen the value of $K_{p}, T_{i}$ and $T_{d}$ were 1.1, 0.1 and 3.7 respectively. The results of the control parameters had error steady state $0.99 \%$ and the settling time of 3.7 seconds at $2.0 \mathrm{sec}$ rise time and the peak value was 0,99. The resulted initial velocity was very fast to approach the desired set point in the sixth second and its speed was remain constant until $100^{\text {th }}$ second.
\end{abstract}

Keywords: Motor DC, PID, Heuristic, Steady State, Rise Time 


\section{PENDAHULUAN}

Motor DC telah dikenal sejak teori gayaLorentz dan induksi elektromagnetik ditemukan. Motor DC sering digunakan karena kemudahannya sehingga dipakai pada berbagai macam keperluan, mulai dari peralatanindustri, rumah tangga hingga ke mainan anak-anak ataupun sebagai piranti pendukung sistem instrumen elektronik. Selama ini, kenyataannya kecepatan putar motor DC mengalami penurunan akibat dari pembebanan sehingga menyebabkan putarannya menjadi lambat dan kecepatannyatidak konstan. Untuk mengatasi hal ini maka diperlukan suatu perancangan sistem kendali kecepatan motor DC agar motor DC tersebut berjalan sesuai dengan kecepatan yang diinginkan.Agar sistem kendali kecepatan motor DC lebih baik maka di perlukan kontroler yang dapat mengendalikan sistem tersebut.Kontroler yang digunakan untuk mengatasi hal ini yaitu dengan kontrolerProportional Integral Derivatif (PID). Konfigurasi standar kontroler PID memiliki parameter-parameter $K_{p}, K_{i}$ dan $K_{d}$ yang dipilih atau ditentukan agar karakteristik plant sesuai dengan kriteria desain yang diinginkan. Parameter umum dalam desain adalah rise-time, settling-time, maximum overshoot dan error steady stateterhadap masukan yang diberikan. Kendali kecepatan motor DC diatur oleh kontroler PID yang di simulasikan dengan perangkat lunak, selanjutnya diperakan melalui GUI (graphic user interface) yang berfungsi sebagai Human Interface, untuk mendapatkan respon kecepatan yang konstan pada set point 1750 RPM pada waktu yang cepat.Pengendalian motor DC ini menggunakan rangkaian berpenguat terpisah, sesuai Gambar 1 (Chapman, 1991).

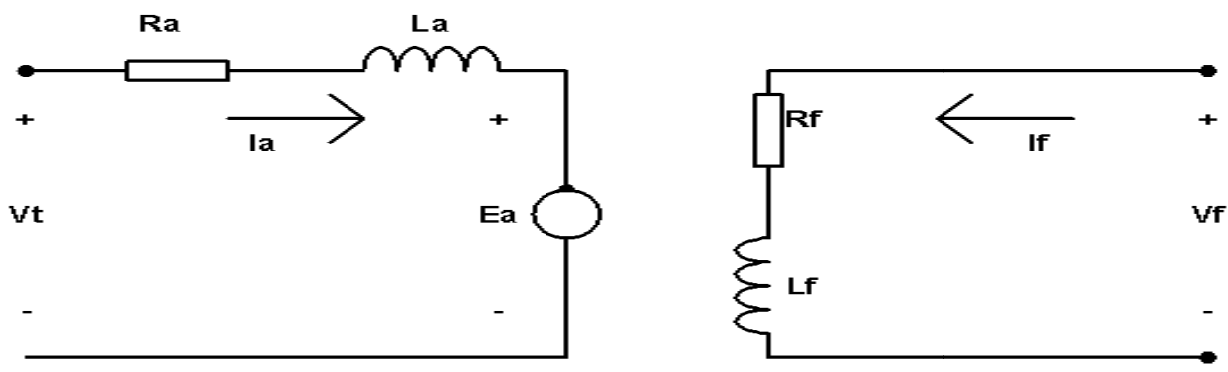

Gambar 1.Rangkaian motor DC berpenguat terpisah

Karena motor DC sering digunakan pada sistem kendali untuk tujuan analisis,sehingga perlu dibuat model matematis motor DC untuk diaplikasikanpada kendali menggunakan gambar rangkaian ekivalen untuk merepresentasikan motor DC dengan magnet permanen. Untuk analisis linier diasumsikan bahwa torsi yang dihasilkan motor sebanding dengan fluks pemisah udara dan arus jangkar. Medan konstan, fluks konstan dan torka mempunyai arah sesuai kumparan magnet, sehingga (Subrahmanyam, 1994):

$$
T_{m}(t)=K_{T} . i_{a}
$$

Karena konstan, maka persamaan(1) dapat ditulis

$$
T_{m}(t)=K_{T}, i_{a}
$$

Tegangan keluaran loop terbuka dari persamaan (2) maka:

$$
e_{t}=K_{T}
$$


Tegangan pada terminal jangkar motor diberikan oleh persamaan :

$$
e_{a}=K_{b} e
$$

Sehingga dengan menggunakan Hukum Kirchoff tegangan diperoleh :

$$
e_{a}=i_{a} R_{a}+L_{a} \frac{d i_{a}}{d t}+e_{b}
$$

Ketika konduktor bergerak pada medan magnet, suatu tegangan dibangkitkan melintasi ujungujungnya. Tegangan ini, emf balik yang sebanding dengan kecepatan motor, berlawanan dengan aliran arus. Hubungan emf balik $\left(e_{b}\right)$ Voltdengan kecepatan motor $\left(\omega_{m}\right) \mathrm{rad} /$ detik adalah

$$
e_{b}=K_{b} \omega_{m}(t)
$$

Persaamaan Motor mempunyai keseimbangan torsi sebagai berikut :

$$
\int \frac{d \omega}{d t}+T_{L}=K_{T} i_{a}
$$

Dari persamaan (7)didapatkan Transformasi Laplace :

$$
\begin{aligned}
& e_{t}=K_{T} \omega \\
& e_{a}(s)=r_{a} l_{a}(s)+s L_{a} l_{a}(s)+e_{b}(s) \\
& e_{b}(s)=K_{b} \omega(s) \\
& s J w(s)+T_{L}(s)=K_{T} l_{a}(s)
\end{aligned}
$$

Dengan menggunakan rumus penguatan Masson (Masson Gain Formula):

$$
T(s)=\frac{\frac{K_{T}}{J L_{a}}}{s^{2}+s\left(L_{a} T_{L}+J R_{a}\right)+\left(R_{a} T_{L}+K_{b} K_{T}\right)}
$$

Dimana $_{a}=$ Tegangan Masukan (Volt), $K_{T}=$ Konstanta Torsi $(\mathrm{Nm} / \mathrm{A}), J=$ Momen Inersia Ekivalen $\left(\mathrm{Kgm}^{2}\right), L_{a}=$ Induktansi kumparan jangkar $(\mathrm{H}), T_{L}=$ Torka Beban $(\mathrm{Nm}), \omega_{m}=$ Kecepatan motor (RPM), $R_{a}=$ Tahanan jangkar $(\Omega), K_{b}=$ Konstanta EMF balik (V/s.rad), $L_{a}=$ Induktansi kumparan jangkar $(\mathrm{H}), l_{d}=$ Arus kumparan jangkar ( $\mathrm{A}$ )

\section{Proporsional Integral Derivatif (PID)}

PID (ProportionallntegralDerivatif) merupakan kontroler untuk menentukan presisi suatu sistem instrumentasi dengan karakteristik adanya umpan balik pada sistem tesebut. Komponen kontroler PID ini terdiri dari tiga jenis yaitu: Proportional, Integratif dan Derivatif. Ketiganya dapat dipakai bersamaan maupun, sendiri-sendiri tergantung dari respon yang kita inginkan terhadap suatu plant (Ogata, 1970).

\section{METODOLOGI PERANCANGAN}

Kendali kecepatan motor DC yang akan dirancang menggunakan kontrol PID (ProportionalIntegral-Derivatif). Kontrol yang dirancang menggunakan bantuan perangkat lunak. Dari perangkat lunak tersebut akan dibuat Blok system untuk kontrol motor DC yang kemudian 
diperagakan ke GUI (Graphic User Interface) yang berfungsi sebagai Human interface.Gambar 2 dibawah ini merupakan konsep perancangan sistem kendali kecepatan motor DC yang dimaksud.

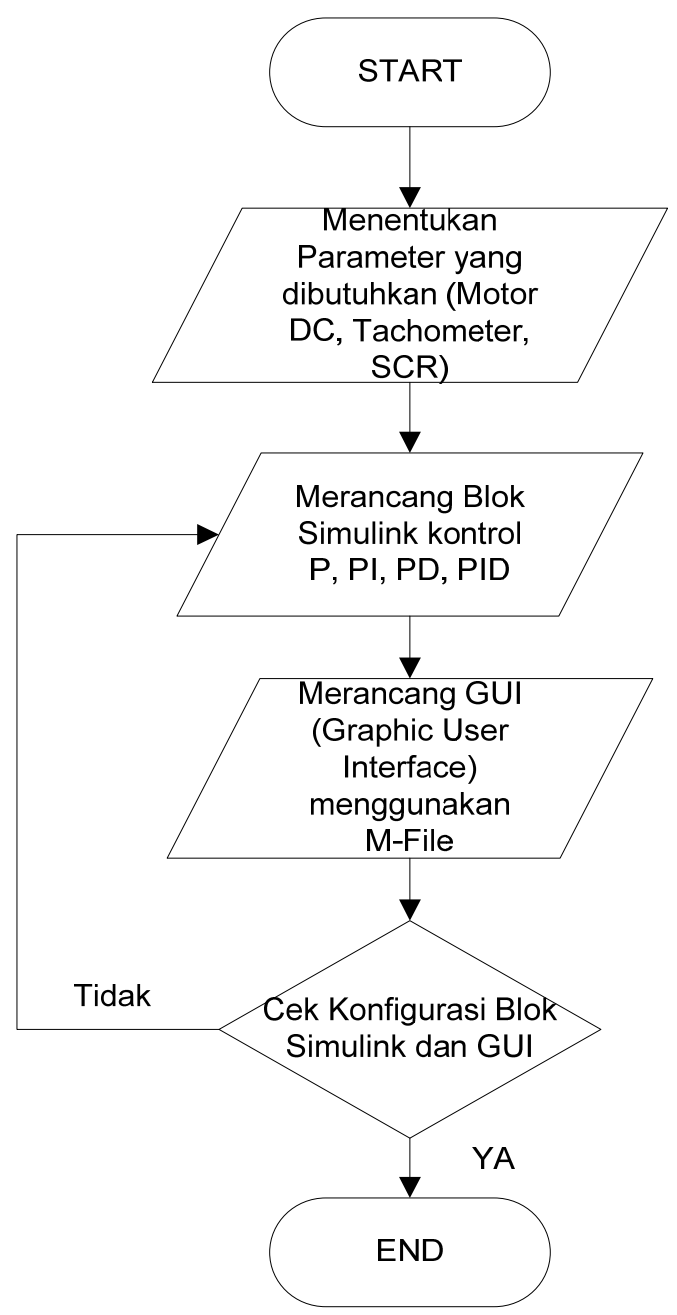

Gambar 2. Flowchartkonsep perancangan kendali kecepatan motor DC

Gambar tersebut menunjukan flowchart konsep perancangan kendali kecepatan motor DC, dimana langkah pertama adalah menentukan parameter yang dibutuhkan untuk data di blok sistem seperti motor DC, tachometer, dan SCR. Selanjutnya membuat rancangan Blok sistem Kontrol P, PI, PD, PID dan langkah yang terakhir membuat GUI (Graphic User Interface) menggunakan M-File.

\subsection{FlowchartPerancangan Sistem Kendali dengan PID}

Gambar 3 menunjukanflowchartyang menentukan parameter PID dengan mencari besarnya nilai dari parameter $K_{p}, K_{i}$ dan $K_{d}$ yaitu dengan cara men-tuning atau penalaan. Proses pemasukan nilai parameter kontrol PID yang dilakukan memiliki beberapa urutan sebagai berikut :

1. Penalaan parameter kontroler dimulai dengan hanya menggunakan kontroler Proportional, kemudian baru ditambahkan kontroler Integral.

2. Penalaan selanjutnya kontroler Proportional hanya ditambahkan kontroler Derivatif saja. 
3. Penalaan terakhir semua parameter kontroler Proportional, Integral dan Derivatif dimasukan nilainya.

4. Melakukan simulasi penalaan parameter kendali PID untuk aplikasi sistem pengendalian kecepatan motor DC dengan memasukkan nilai model matematika keseluruhan yang telah dihitung sebelumnya (Ogata, 1994).

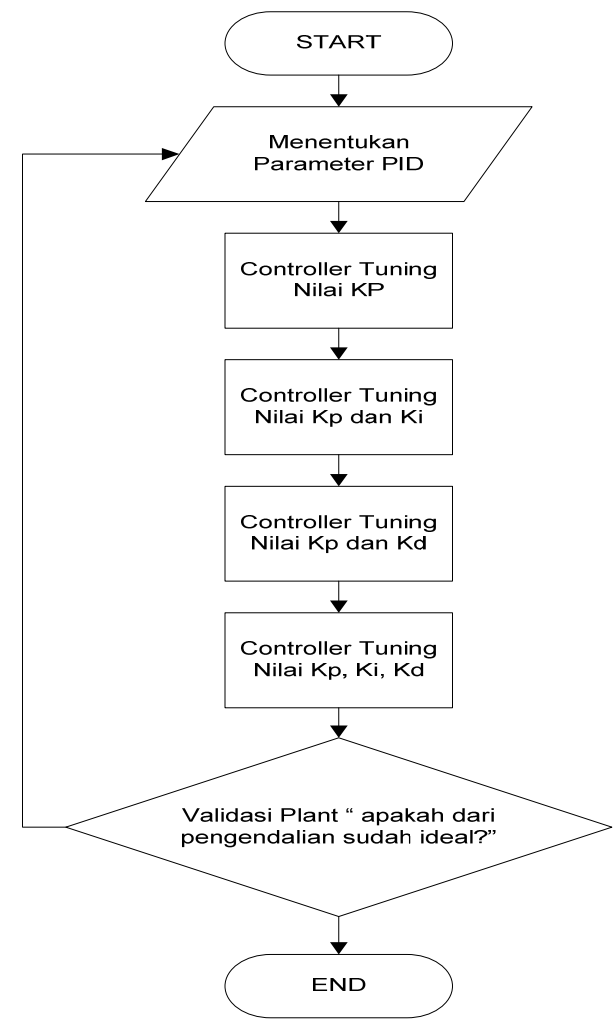

Gambar 3. Flowchartpenalaan pada kontrol PI D untuk mendapatkan nilai parameter

\subsection{Pengumpulan Data Spesifikasi}

\subsubsection{Spesifikasi Motor DC}

Pada rancangan ini motor DC yang digunakan adalah type PITMAN Series GM 14900 type 1, dimana spesifikasi motor yang digunakan (Pittman, 2013).

$\begin{array}{ll}\text { No-Load Speed } & =4230 \mathrm{rpm} \\ \text { No-Load Current } & =0,20 \mathrm{~A} \\ \text { Konstanta Aplifier }\left(\mathrm{K}_{\mathrm{A}}\right) & =10 \mathrm{~N}-\mathrm{m} / \mathrm{A} \\ \text { Konstanta torsi Motor }\left(\mathrm{K}_{\mathrm{T}}\right) & =9,46 \mathrm{Nm} / \mathrm{A} \\ \text { Back-EMF Kosntan }\left(\mathrm{K}_{\mathrm{b}}\right) & =6,99(\mathrm{~V} / \mathrm{krpm}) \\ \text { Torka Beban }\left(\mathrm{T}_{\mathrm{L}}\right) & =3,53 \mathrm{Nm} \\ \text { Momen Inersia }(\mathrm{J}) & =1,13 \times 10^{-5} \mathrm{~kg} / \mathrm{m}^{2} \\ \text { Induktansi jangkar }\left(\mathrm{L}_{\mathrm{a}}\right) & =4,10 \mathrm{mH} \\ \text { Resistansi }\left(\mathrm{R}_{\mathrm{a}}\right) & =4,45 \mathrm{ohm}\end{array}$

Dari data tersebut, nilai Transformasi Laplace dapat dicari dengan menggunakan persamaan (12) seperti dibawah ini: 


$$
\begin{aligned}
T(s) & =\frac{\frac{K_{T}}{J L_{a}}}{s^{2}+s\left(L_{a} T_{L}+J R_{a}\right)+\left(R_{a} T_{L}+K_{b} K_{T}\right)} \\
& =\frac{\frac{9.46}{4.10 \times 1.13 \times 10^{-5}}}{s^{2}+s(4.10 \times 3.53)+\left(1.13 \times 10^{-5} \times 4.45\right)+(4.45 \times 3.53+6.99 \times 9.46)} \\
& =\frac{20403}{s^{2}+14.473 s+81.833}
\end{aligned}
$$

\subsubsection{Spesifikasi Tachometer}

Sensor yang digunakan adalah tachometer yang prinsip kerjanya terjadi proses konversi langsung antara kecepatan dan tegangan. Masukan sensor kecepatan berupa kecepatan putar dari motor DC $\left(\omega_{m}\right)$. Setelah dikonversi, keluaran dari sensor adalah tegangan dalam volt. Sensor ini memiliki tegangan 6,5 Volt dengan kecepatan putar mencapai $4230 \mathrm{rpm}$, sehingga gain dari sensor kecepatan adalah sebagai berikut (Shearer, 1990).

$$
K=\frac{E}{\omega_{m}}=\frac{6.5 \mathrm{~V}}{4230 \mathrm{rpm}}=1,53 \times 10^{-3} \mathrm{~V} / \mathrm{rpm}
$$

\subsubsection{SCR (Silicon Controlled Rectifier)}

Aktuator yang digunakan untukmengendalikan kecepatan motor DC adalah SCR(Silicon Controlled Rectifier) yang memilikitegangan DC 180 volt dengan tegangan keluaran sebesar 220 volt. Motor DC yang akan dikendalikan memiliki tegangan input 30,3 Volt, dengan kecepatan putar antara 0-4230 RPM, sehingga diperoleh gain untuk SCR sebesar (Shearer, 1990):

$$
K_{S C R}=\frac{\text { output_ } V_{d c}}{\text { Input_ } V_{m}}=\frac{220 \mathrm{Volt}}{180 \mathrm{Volt}}=1.22 \mathrm{Volt}
$$

\subsection{Perancangan Sistem Kendali Kecepatan Motor DC Tanpa Menggunakan Kontroler PI D}

Perancangan pengendali kecepatan motor DC yang dilakukan tanpa menggunakan kontroler PID yaitu dilakukan dengan sistem open loop. Model simulasi pengendalian kecepatan motor DC dengan sistem open loopterlihat pada Gambar 4.

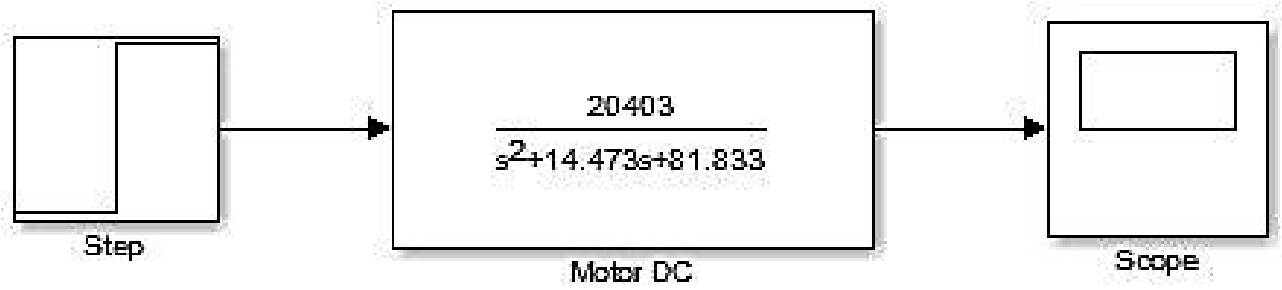

Gambar 4. Model kendali open loop motor DC

\subsection{Perancangan Sistem Kendali Kecepatan Motor DC Menggunakan Kontroler PID}

Pada rancangan kontrol PIDini menggunakan jenis Motor DC PITMAN Series GM 14900 type 14X01. Perancangan dilakukan dengan beberapa kontrol yaitu:

\subsubsection{Rancangan Kontrol Proportional}


Gain unit control proportional dapat berupa bilangan bulat, atau bilangan pecahan. Semakin besar nilai gain akan menyebabkan pengendali semakin reaktif terhadap error.Hal ini ditandai oleh adanya overshoot pada kondisi transient dan sebaliknya. Gambar 5merupakan rancangan diagram blok menggunakan kontrol proportional saja untuk mengendalikan kecepatan motor DC.

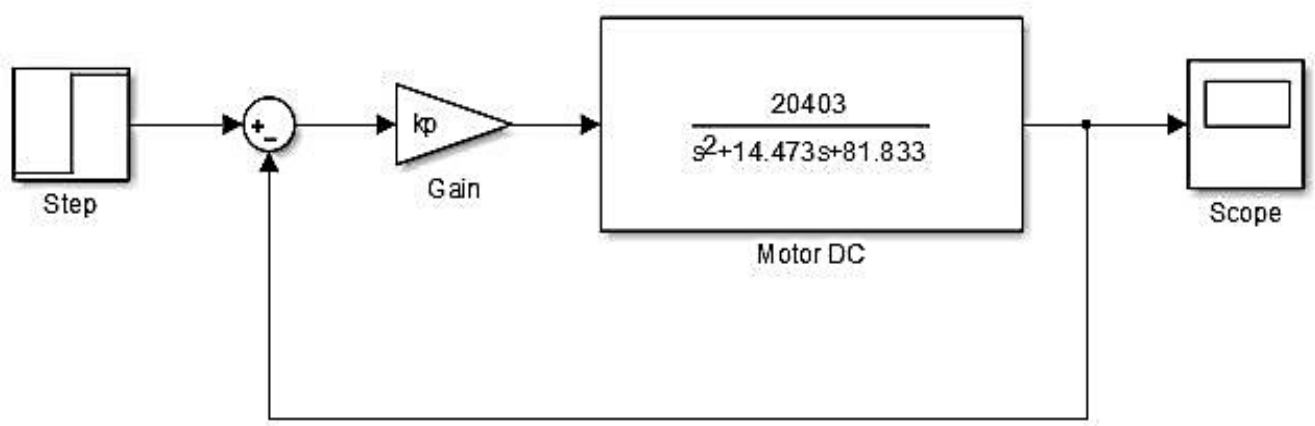

Gambar 5. Kontrol Proportional

\subsubsection{Rancangan Kontrol Proportional Integral}

Kekurangan pengendali proporsional dapat dihilangkan dengan memasukkan elemen pengendali integral. Elemen pengendali integral mempunyai kelemahan dalam respon dinamik, dimana pengaturan lingkar tertutup berosilasi dengan amplitudo yang mengecil secara perlahan atau bahkan amplitudo yang membesar. Biasanya kedua hal ini tidak diinginkan.Gambar 6 adalah rancangan diagram blokmenggunakan kontrol Proportional dan Integral untuk mengatur kecepatan motor DC.

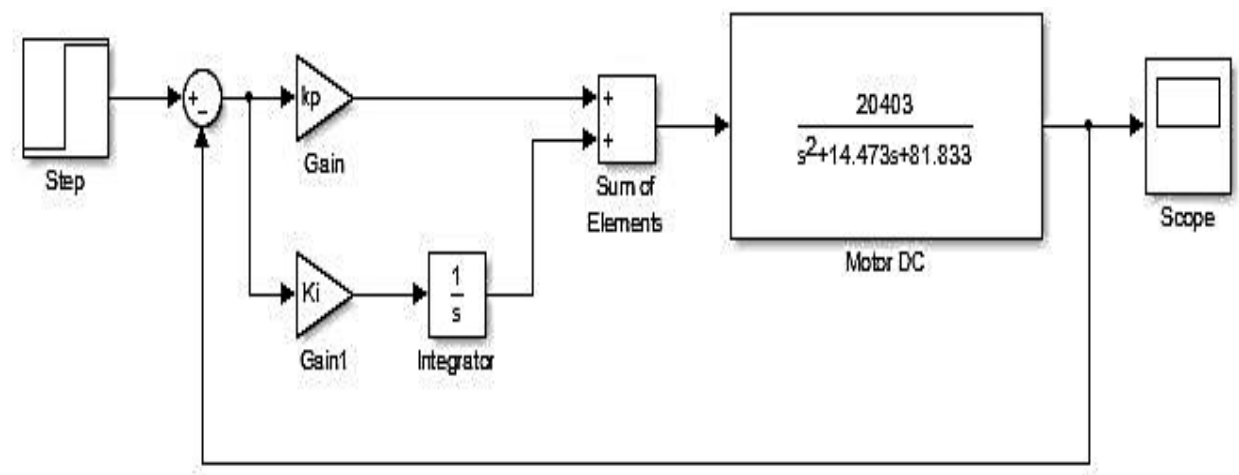

Gambar 6. Kontrol Proportional Integra/ pada Simulink

\subsubsection{Rancangan Kontrol Proportional Derivatif}

Kendali derivatif selalu digunakan bersama-sama dengan aksi proportional. Aksi kendali derivatif mendahului kesalahan penggerak, mengawali aksi koreksi dini dan cendrung memperbesar kestabilan sistem. Gambar 7 merupakan rancangan diagram blokmenggunakan kontrol Proportional dan Derivatif, tanpa menggunakan kontrol Integral untuk mengatur kecepatan motor DC. 


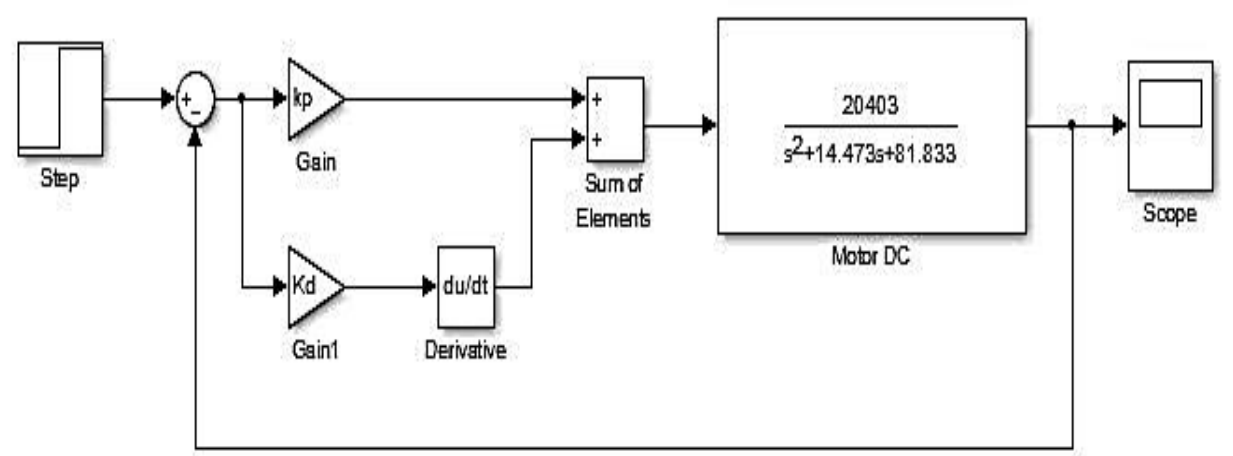

Gambar 7. Kontrol Proportional dan Derivatif pada Simulink

\subsubsection{Rancangan Kontrol Proportional Integral Derivatif}

Pada perancangan sistem kontrol PID yang perlu dilakukan adalah mengatur parameter $\mathrm{P}, \mathrm{I}$ atau $\mathrm{D}$ agar tanggapan sinyal keluaran sistem sesuaimasukan, sebagaimana yang diinginkan sehingga mendapatkan nilai ideal, dengan melakukan penalaan nilai $\mathrm{K}_{\mathrm{p}}, \mathrm{K}_{\mathrm{i}}, \mathrm{K}_{\mathrm{d}}$. Gambar 8 adalah rancangan diagram blok yang diperagakan ke GUI yang berfungsi sebagai Human interface.

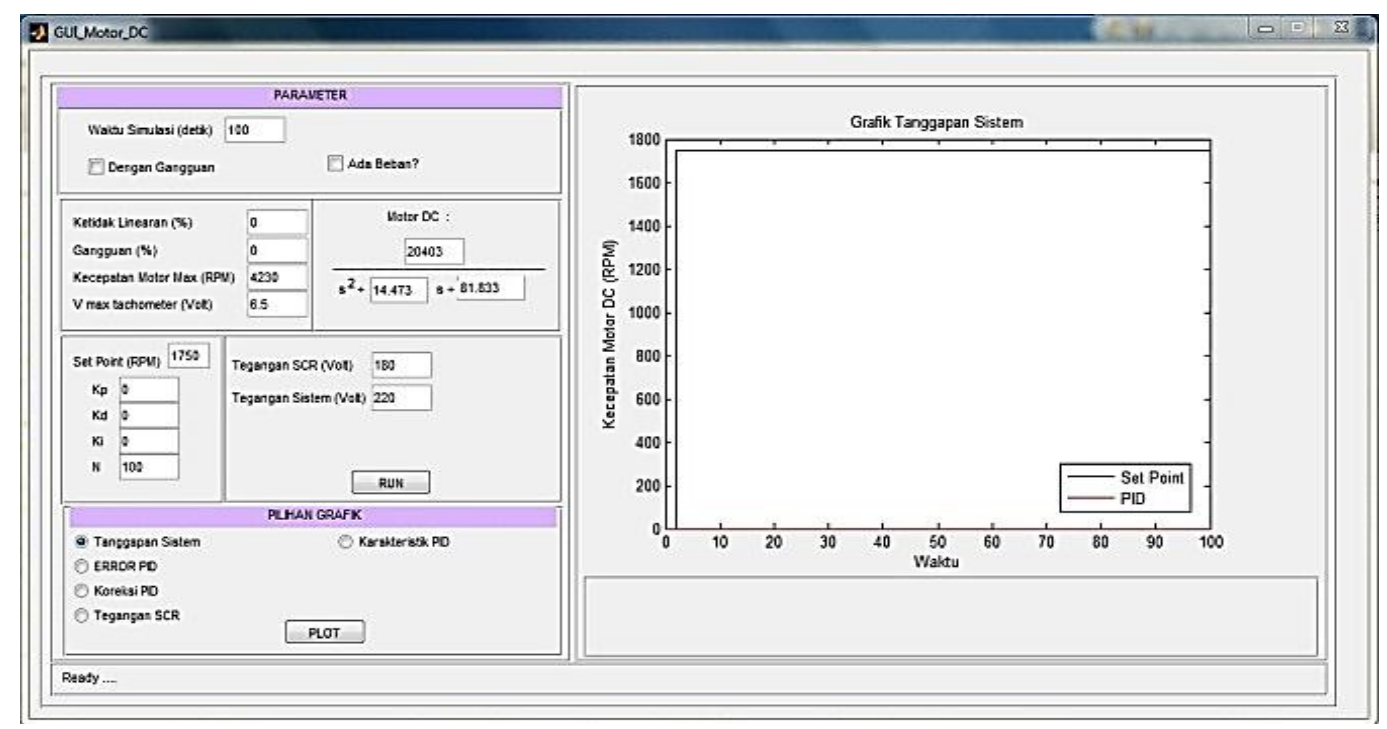

Gambar 8. Rancangan grafik GUI

Gambar 8 adalah rancangan Human Interface yang diaplikasikan ke GUI. Padatampilan GU/8 mengandungtugas, perintah, atau komponen program yang mempermudah user (pengguna) dalam menjalankannya. 


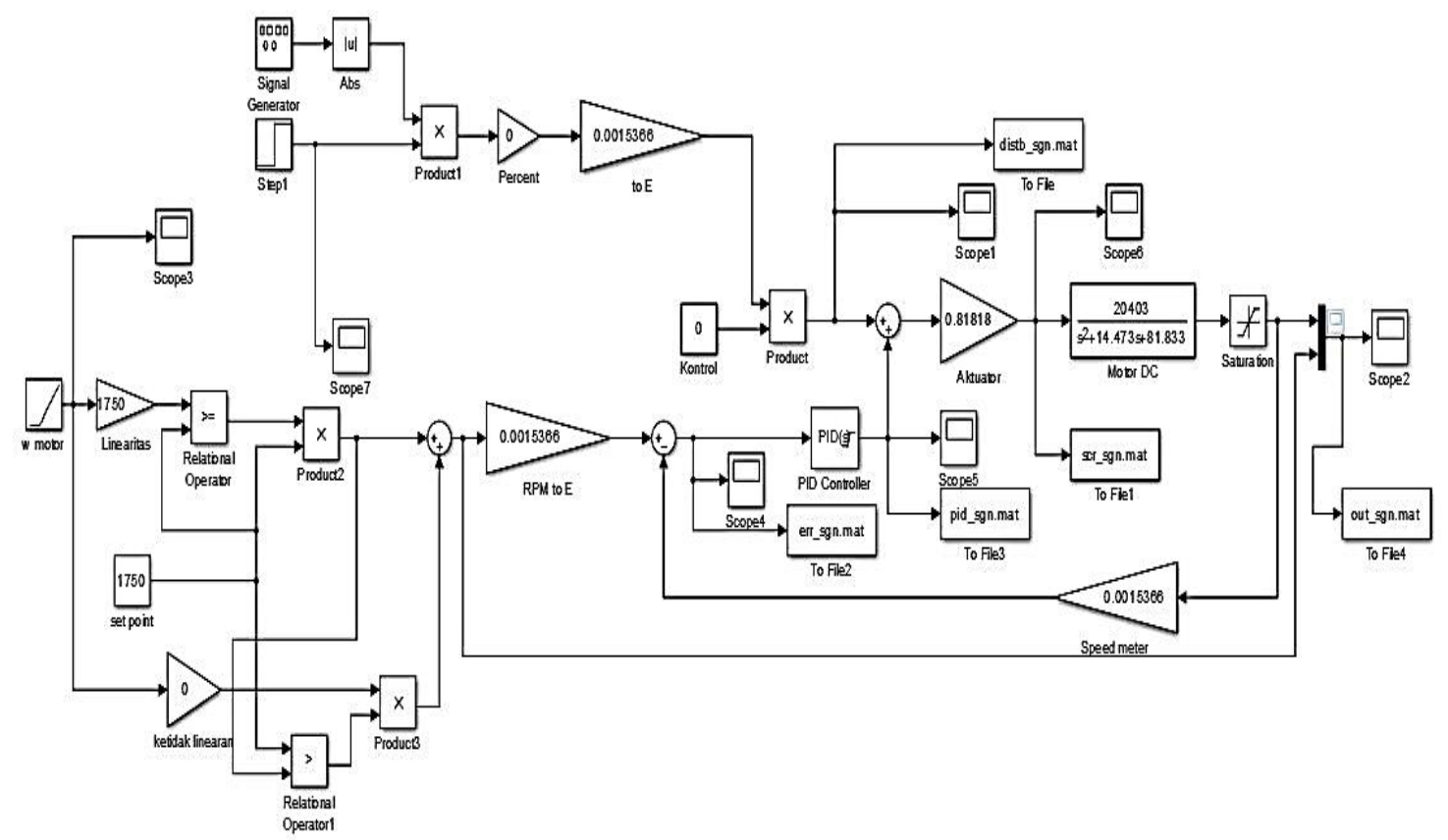

Gambar 9. Kontrol Porportional, Integral dan Derivatif pada Simulink

Gambar 9adalah rancangan diagram bloksistemuntuk kontrolerProportional, Integral dan Derivatif untuk tampilan GUI. Sinyal step diberikan untuk set point sebesar 1750 RPM, karena keluaran adalah data linear sebanding dengan waktu simulasinya, misalnya 100 putaran, keluaran hanya sampai 100 putaran sehingga diperlukan pengubah ke data actual (RPM) dengan memasukan blokGain. Blok ketidaklinearan diberikan dengan asumsi sewaktu mengubah setpoint, terjadi gangguan gesekan di potensiometer. Blok Relational Operator berfungsi jika masukan Port1 lebih besar atau sama dengan set point, maka nilainya 1, dan jika data pengaturan masih lebih kecil dari set point maka keluaran blok relational operator bernilai 0 . Set point adalah $E$ (gaya gerak listrik), keluaran tachometer juga $E$ (gaya gerak listrik) dengan keluaran blok $\omega_{\mathrm{m}}($ nilai $R P M)$, maka keluaran blok set point harus menjadi besaran $E$ (ggl) dengan blok RPM ke $E$. Nilai E mengambil dari nilai pengubah tachometer, karena tachometer juga berfungsi sebangai pengubah RPM ke E. Nilai set point yang sudah di-set sebesar 1750 RPM merupakan batas sinyal masukan (kecepatan) pada scope, serta pada blok kontroler PID, yang berfungsi untuk mencari kecepatan motor DC yang ideal dengan cara mencari nilai penalaan parameter $\mathrm{K}_{\mathrm{p}}, \mathrm{K}_{\mathrm{i}}, \mathrm{K}_{\mathrm{d}}$. Blok transfer function berfungsi untuk memasukkan nilai parameter pada motor $D C$, selanjutnya memasukkan nilaiparameter $K_{p}, K_{i}, K_{d}$ yang dimasukkan pada blok kontroler PID, untuk mengatur kecepatan motor DC. Blok saturation berfungsi untuk membatasi keluaran agar tidak melampaui kecepatan maksimum motor, sebesar 4230 RPM, serta dengan nilai tersebut tachometer akan mengeluarkan tegangan 6.5 volt dan menghasilkan sinyal output pada scope.

\section{HASI L SI MULASI DAN PEMBAHASAN}

\subsection{Pengujian Sistem}

Dari hasil perancangan pada simulasi kendali kecepatan motor DC yang telah dilakukan, yaitu dengan adanya pengendalian tanpa kontroler PID dan dengan adanya pengendalian dari kontroler PID, maka diperoleh hasil rancangan yang dapat dianalisis sebagai berikut. 


\subsubsection{Analisis Pengujian Sistem Kendali Kecepatan Motor DC Tanpa Menggunakan Kontroler PI D}

Pengujian rancangan kendali motor DC ini dilakukan tanpa menggunakan kontroler PID. Gambar 10 berikut merupakan grafik yang dihasilkan dari sistem open loop motor DC tanpa kontrol PID.

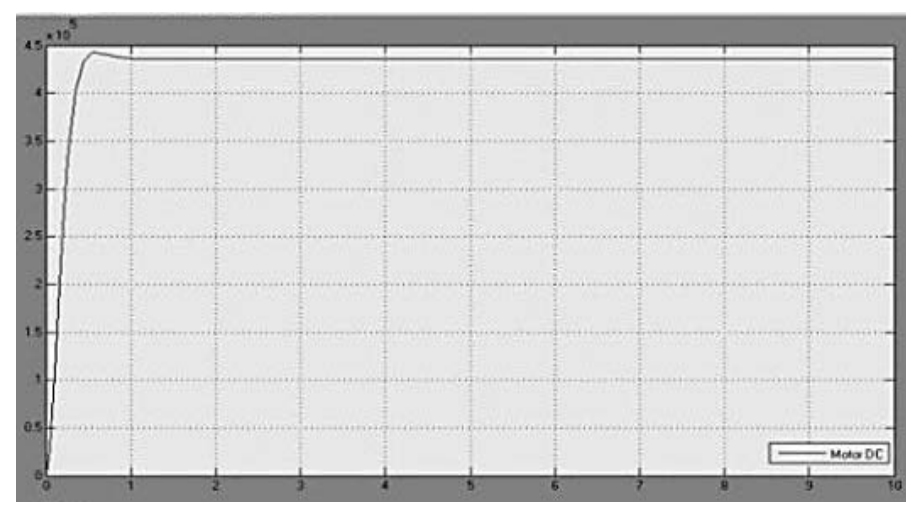

Gambar 10. Tampilan Respon Motor Dc tanpa kontrol PID

Dari gambar tersebut dapat dilihat hasil dari kinerja respon motor DC tanpa pengendalian yang diberikan input sinyal step bahwa respon bisa mengikuti set point sebesar $1750 \mathrm{rpm}$ sampai dengan 10 detik tetapi steady state nya masih besar.

\subsubsection{Analisis Pengujian Sistem Kendali Kecepatan Motor DC dengan menggunakan Kontroler PI D}

\subsubsection{Uji Penalaan Parameter Kontrol dengan Memasukkan Nilai Proportional}

Respon penalaan parameter kontrol PID sistem pengendalian kecepatan motor DC dengan $\mathrm{K}_{\mathrm{p}}=$ 0,1 .

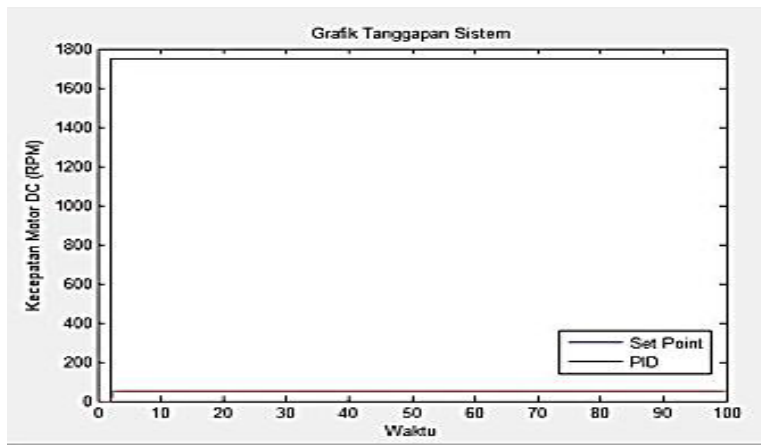

(a)

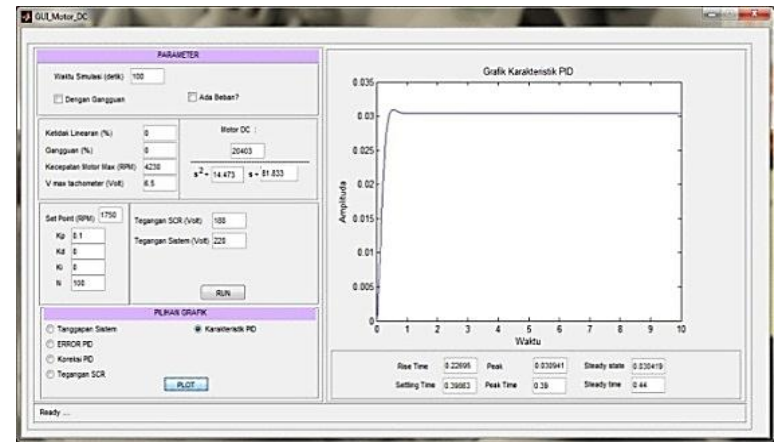

(b)

Gambar 11 (a)Grafik tanggapan sistem $K_{p}=0.1$

11 (b) Grafik karakteristik PID $K_{p}=0.1$

Gambar 11 (a)adalah grafik tanggapan sistem motor DCpada $K_{p}=0,1$ dengan set point 1750 RPM menghasilkan kecepatan sebesar 50 RPM sampai dengan 100 detik. Gambar 11 (b) adalah Hasil respon grafik karakteristik PID menghasilkan nilai rise Time $=0,22$, settling Time $=0,39$, peak $=0,03$, dan nilai steady state $=0,030$. 


\subsubsection{Uji Penalaan Parameter Kontrol dengan Memasukkan Nilai Proportional Integral}

Respon penalaan parameter kontrol PID sistem pengendalian kecepatan motor DC dengan $\mathrm{K}_{\mathrm{p}}=$ $0,2, K_{i}=0,6$.

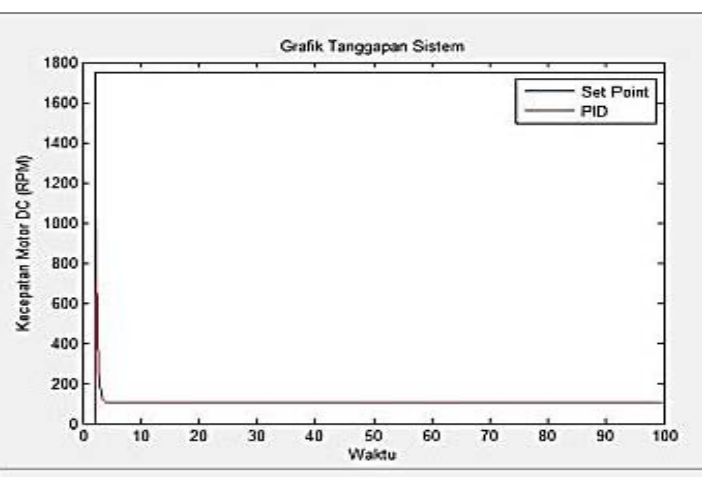

(a)

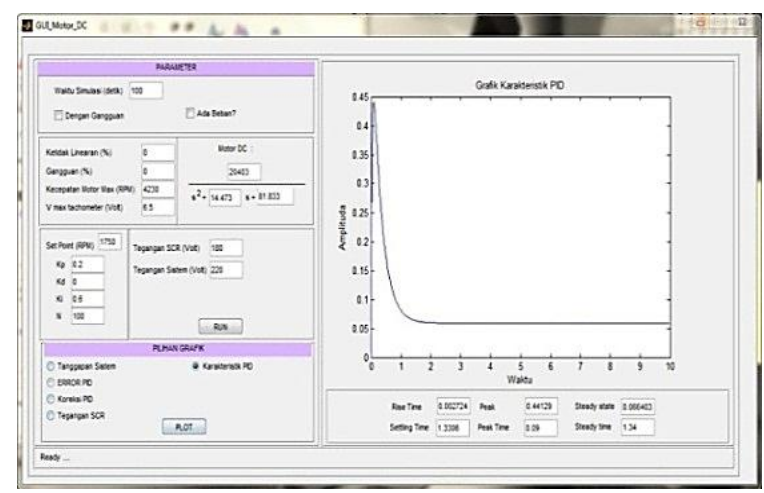

(b)

Gambar 12 (a)Grafik tanggapan sistem $K_{p}=0,2, K_{i}=0,6$ 12 (b) Grafik karakteristik PID $K_{p}=0,2, K_{i}=0,6$

Gambar 12(a) adalah grafik tanggapan sistem motor DC pada $K_{p}=0,2, K_{d}=0$,6dengan set point 1750 RPM menghasilkan kecepatan sekitar 1000 RPM, tetapi kecepatan yang dikontrol mengalami penurunan sekitar 100 RPM pada detik kelima.Gambar 12 (b) adalah hasil respon karakteristik PID menghasilkannilai rise time $=0,002$, settling time $=1,33$, peak $=0,44$, dan nilai steady state $=0,066$.

\subsubsection{Uji Penalaan Parameter Kontrol dengan Memasukkan Nilai Proportional, Derivatif}

Respon penalaan parameter kontrol PID sistem pengendalian kecepatan motor DC dengan $\mathrm{K}_{\mathrm{p}}=$ $3,2, K_{d}=1,8$.

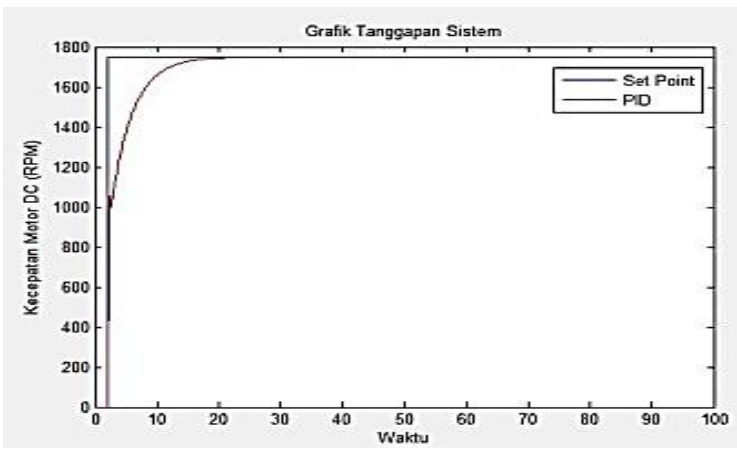

(a)

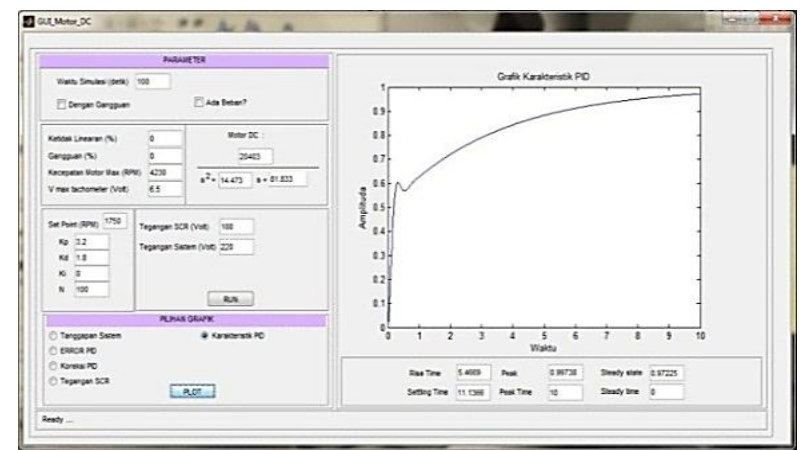

(b)

Gambar 13 (a)Grafik tanggapan sistem $K_{p}=3,2, K_{d}=1,8$

13 (b) Grafik karakteristik PID $K_{p}=3,2, K_{d}=1,8$

Gambar13 (a) adalah grafik tanggapan sistem motor DC pada $K_{p}=3,2, K_{d}=1,8$ dengan set point 1750 RPM menghasilkan kecepatan sebesar 1000 RPM tetapi kecepatan yang dihasilkan tidak konstan sampai dengan detik kelima dan mengalami kenaikan ke set point 1750 RPM 
pada detik ke-25. Gambar 13 (b) adalah grafik karakteristik PID menghasilkan nilai rise time = 5,466 , settling time $=11,136$, peak $=0,99$, dan nilai steady state $=0,97$.

\subsubsection{Uji Penalaan Parameter Kontrol dengan Memasukkan Nilai Proportional, Integral dan Derivatif}

Respon penalaan parameter kontrol PID sistem pengendalian kecepatan motor DC dengan $\mathrm{K}_{\mathrm{p}}=$ $1,1, K_{i}=0,1, K_{d}=3,7$.

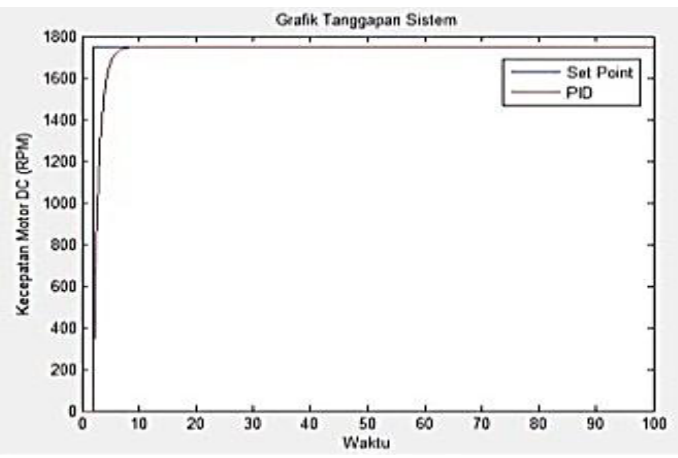

(a)

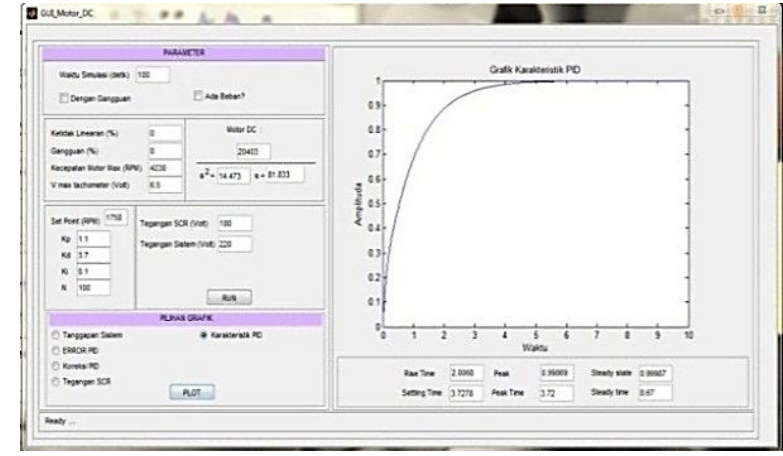

(b)

Gambar 14 (a)Grafik tanggapan sistem $K_{p}=1,1, K_{i}=0,1, K_{d}=3,7$

(b) Grafik karakteristik PI D $K_{p}=1,1, K_{i}=0,1, K_{d}=3,7$

Gambar 14 (a)merupakan grafik tanggapan sistem motor DC pada $K_{p}=1,1, K_{i}=0,1, K_{d}=3,7$ dengan set point 1750 RPM menghasilkan kecepatan awal yang ideal mendekati set point sebesar 1750 RPM pada detik keenam. Kecepatan yang dihasilkan pada kontroler ini adalah kecepatan yang konstan sampai dengan 100 detik dan kecepatan awal yang dihasilkan berlangsung cepat dan bertahap.Gambar 14 (b)adalah grafik karakteristik PID menghasilkan nilai rise time $=3,72$, settling time $=3,72$, peak $=0,99$, dan nilai steady state $=0,999$.

Tabel 1 merupakan hasil uji dengan metode Heuristik untuk mendapatkan parameter yang ideal untuk mengendalikan kecepatan motor $D C$, dengan $K_{p}, K_{i}$ dan $K_{d}$ berturut-turut sebesar $1,1,0,1$ dan 3,7 serta mempunyai grafik tegangan keluaran PID dan grafik tegangan SCR pada Gambar 15 .
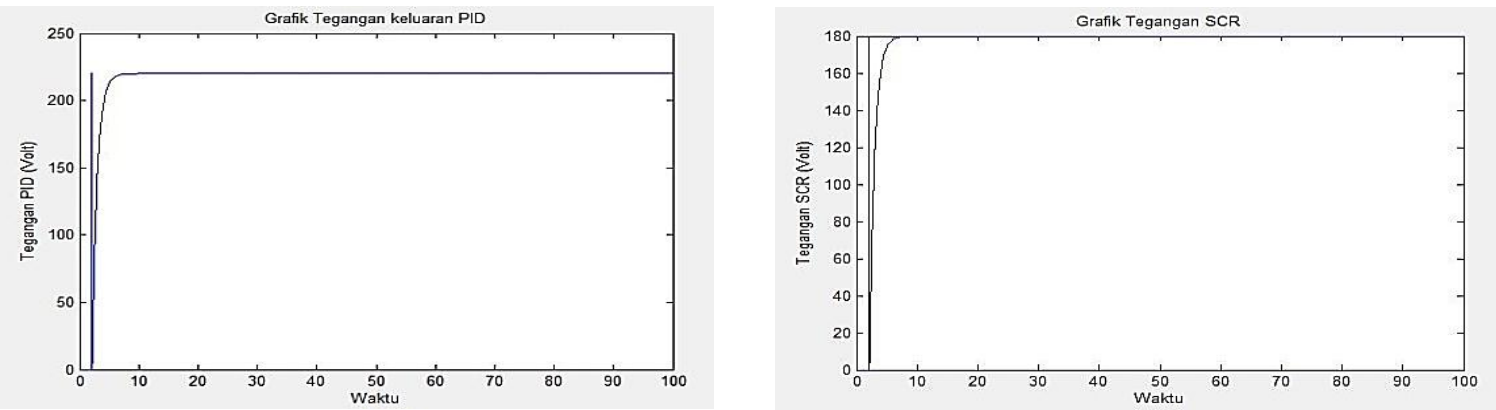

Gambar 15.Grafik Tegangan keluaran PI DGambar 16. Grafik Tegangan SCR

Gambar 15 pada $K_{p}=1,1, T_{i}=0,1, T_{d}=3,7$ mengahasilkan nilai tegangan pada PID sebesar 220 volt pada waktu 100 detik sesuai set point yang diinginkan. 
Gambar 16 pada $\mathrm{K}_{\mathrm{p}}=1,1, \mathrm{~T}_{\mathrm{i}}=0,1, \mathrm{~T}_{\mathrm{d}}=3,7$ menghasilkan nilai tegangan pada SCR sebesar 180 volt pada waktu 100 detik sesuai set point yang diinginkan.

Tabel 1. Hasil Respon Penalaan Parameter kontrol PID dengan Metode Heuristik untuk Pengendalian kecepatan motor DC

\begin{tabular}{|c|c|c|c|c|c|c|c|}
\hline $\begin{array}{l}\text { Kecepatan } \\
\text { Motor DC }\end{array}$ & \multicolumn{3}{|c|}{$\begin{array}{c}\text { Uji Metode } \\
\text { Heuristik }\end{array}$} & $\begin{array}{c}\text { Settling } \\
\text { Time }\end{array}$ & $\begin{array}{l}\text { Rise } \\
\text { Time }\end{array}$ & $\begin{array}{l}\text { Error } \\
\text { Steady } \\
\text { State }\end{array}$ & Peak \\
\hline \multirow{27}{*}{$\begin{array}{l}1750 \\
\text { RPM }\end{array}$} & $K_{p}$ & $K_{i}$ & $K_{d}$ & Detik & Detik & $\%$ & \\
\hline & 0.1 & 0 & 0 & 0.39 & 0.22 & 0.03 & 0.03 \\
\hline & 0.9 & 0 & 0 & 0.58 & 0.17 & 0.22 & 0.22 \\
\hline & 2.4 & 0 & 0 & 0.49 & 0.12 & 0.43 & 0.46 \\
\hline & 3 & 0 & 0 & 0.46 & 0.11 & 0.49 & 0.53 \\
\hline & 3.8 & 0 & 0 & 0.43 & 0.10 & 0.55 & 0.61 \\
\hline & 0.2 & 0.6 & 0 & 1.33 & 0.02 & 0.06 & 0.44 \\
\hline & 0.1 & 1.1 & 0 & 1.98 & 0.00 & 0.04 & 0.59 \\
\hline & 1.9 & 1.4 & 0 & 1.45 & 0.01 & 0.38 & 0.68 \\
\hline & 0.9 & 2.2 & 0 & 2.66 & 0.00 & 0.23 & 0.76 \\
\hline & 3.5 & 2.2 & 0 & 1.35 & 0.01 & 0.53 & 0.77 \\
\hline & 0.1 & 0 & 0.1 & 127.2 & 66.8 & 0.28 & 0.99 \\
\hline & 0.9 & 0 & 0.6 & 24.5 & 13.5 & 0.82 & 0.99 \\
\hline & 2 & 0 & 0.9 & 19.4 & 10.1 & 0.89 & 0.99 \\
\hline & 3.2 & 0 & 1.8 & 11.1 & 5.4 & 0.97 & 0.99 \\
\hline & 3.7 & 0 & 2.9 & 7.19 & 3.4 & 0.99 & 0.99 \\
\hline & 0.1 & 0.1 & 0.1 & 127.1 & 66.7 & 0.28 & 0.99 \\
\hline & 0.9 & 0.1 & 0.1 & 13,1 & 7.26 & 0.95 & 0.99 \\
\hline & 1 & 0.3 & 1.3 & 11.1 & 6.3 & 0.97 & 0.99 \\
\hline & 1.8 & 0.3 & 1.4 & 11.9 & 6.4 & 0.96 & 0.99 \\
\hline & 1.7 & 0.5 & 1.3 & 12.5 & 6.8 & 0.95 & 0.99 \\
\hline & 2 & 0.7 & 1.9 & 8.7 & 4.8 & 0.98 & 0.99 \\
\hline & 1.5 & 0.9 & 2.5 & 5.8 & 3.4 & 0.99 & 0.99 \\
\hline & 1.3 & 1.2 & 3 & 4.3 & 2.8 & 0.99 & 0.99 \\
\hline & 1.2 & 1.9 & 3.5 & 3.3 & 2.6 & 0.99 & 1.01 \\
\hline & 1.1 & 2.5 & 3.6 & 5.6 & 2.7 & 1.01 & 1,03 \\
\hline & 1.1 & 0.1 & 3.7 & 3.7 & 2.0 & 0.99 & 0.99 \\
\hline
\end{tabular}

Percobaan pada kondisi ketika kontrol diberi gangguan, gangguan itu berasal dari SCR yang diberi kelebihan tegangan.Pada kondisi ini, respon sistem yang diamati terlihat pada Gambar 17 (Ogata K, 1994).

Gambar 17 terlihat bahwa ketika kontroler PID $K_{p}=1,1, T_{i}=0,1, T_{d}=3,7$ diberi gangguan berupa kelebihan tegangan pada SCR, maka kecepatan motor DC untuk mencapai set point 1750 RPM terbukti tidak mengalami penurunan atau kenaikan yang signifikan. Kecepatan motor masih tetap konstan mengikuti set point yang diinginkan dan parameter yang dihasilkan tidak berubah saat diberi gangguan Settling time 3,72, Rise Time 2,00 danSteady State 0,99 \% pada peak 0,99. 


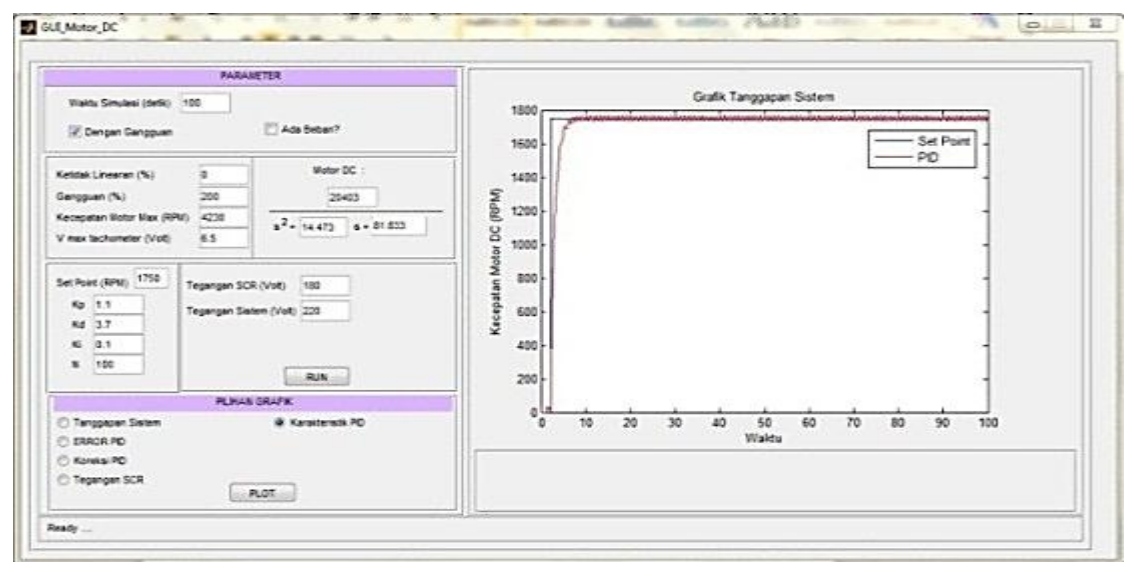

Gambar 17.Grafik dari tanggapan sistem saat diberi gangguan

\section{KESI MPULAN}

Berdasarkan hasil dari percobaan simulasi sistem pengendalian kecepatan motor DC menggunakan kontrol PID dan analisis data yang telah diperoleh, dapat ditarik simpulan sebagai berikut.

1. Dari simulasi yang dilakukan dengan Metode Heuristik atau penalaan terbukti mampu memberikan kriteria performansi sistem kendali yang baik dilihat dari perbandingan nilai error steady state yang dihasilkan pada pengendali tanpa menggunakan kontroler PID dan dengan menggunakan kontroler PID hanya 0,99\%.

2. Penalaan parameter kendali PID untuk mengendalikan kecepatan motor DC yang dipakai pada perancangan ini mampu memberikan respon pengendalian yang paling ideal, dengan nilai $\mathrm{K}_{\mathrm{p}}=1,1, \mathrm{~T}_{\mathrm{i}}=0,1$ dan $\mathrm{T}_{\mathrm{d}}=3,7$ terlihat dari hasil grafik yang dihasilkan Rise time-nya cukup cepat2,0detik dengan settling time-nya sangat cepat3,72 detik, sedangkan error steady state-nya hanya 0,99 \%.Kecepatan yang dikontrol juga tidak mengalami penurunan dan respon yang dihasilkan sangat cepat untuk mencapai set point pada detik keenam.

3. Pada saat kecepatan motor DC diberi gangguan berupa tegangan kelebihan SCR terbukti tidak mengalami penurunan atau kenaikan kecepatan yang signifikan, dan masih mengikuti set point yang diberikan sampai dengan detik ke-100.

\section{DAFTAR RUJ UKAN}

Chapman, Stephen.(1991). Electric Machinery Fundamentals edisi 2. United State : McGraw-Hill Companies.

Ogata, Katsuhiko.(1970). Teknik Kontrol Automatik Edisi 2 J ilid 1. Jakarta : Prentice Hall.

Ogata K. (1994). Solving Control Engineering Problems with MATLAB. Prentice Hall International, Inc : Prentice Hall.

Pittman. (2013). Buletin motor DC catalog GM 14900 type 1.

Shearer, J. Lowen. (1990). Dynamic Modeling and Control of Engineering Systems, Macmillan Publishing Company. New York : Prentice Hall Int.

Subrahmanyam, Vedam.(1994). Electrical Drives "Concepts and Aplications", Tata McGraw-Hill Company Limited. New Delhi : McGraw-Hill Companies. 